Article

\title{
Numerical Prediction and Reduction of Hat-Shaped Part Springback Made of Dual-Phase AHSS Steel
}

\author{
Peter Mulidrán *, Emil Spišák, Miroslav Tomáš, Ján Slota $@$ and Janka Majerníková $\mathbb{}$ \\ Institute of Technology and Materials Engineering, Faculty of Mechanical Engineering, Technical University of \\ Košice, Mäsiarska 74, 04001 Košice, Slovakia; emil.spisak@tuke.sk (E.S.); miroslav.tomas@tuke.sk (M.T.); \\ jan.slota@tuke.sk (J.S.); janka.majernikova@tuke.sk (J.M.) \\ * Correspondence: peter.mulidran@tuke.sk; Tel.: +421-55-602-3519
}

Received: 3 July 2020; Accepted: 19 August 2020; Published: 20 August 2020

\begin{abstract}
The springback in the sheet metal forming process refers to the change of shape after the load removal. It is usually undesirable, causing problems in the subsequent forming operations, in the assembly and negatively affects the quality of the final product. Numerical prediction of the springback with the use of the numerical simulation is crucial for the reduction of forming tool try-outs, reducing manufacturing costs and increasing the accuracy of the stamped part. In this work, numerical simulation was used for the springback prediction of the hat-shaped part made of advanced high-strength dual-phase steel HCT600X $+Z$. These numerical predictions were performed with the use of various combinations of material models to try to improve the prediction results. Furthermore, this work includes the proposed springback reduction measure. The reduction of the springback was achieved by the tool design which includes a counterpunch. The springback analysis was carried out in the side view of the formed part; the springback prediction results were compared with the experimental values.
\end{abstract}

Keywords: springback; springback prediction; springback reduction; numerical simulation

\section{Introduction}

High-strength steels have been used in the automotive industry for over three decades. The use of these steels can reduce the weight of the car as well as increase passive safety. Reducing the car's weight improves fuel economy, resulting in lower $\mathrm{CO}_{2}$ emissions. The main disadvantages of the high-strength steels compared to conventional drawing steels are worse formability and greater springback effect. The most common measure against the springback of the stamped parts is to design the forming tool in such a way that its geometry compensates for the springback.

The springback phenomenon involves small strains, similar in magnitude to other elastic deformation of metallic materials. As such, it was formerly considered a simple phenomenon relative to the large-strain deformation required for most of the forming operations. Nowadays, high precision is needed for the large strain plastic response that directly affects the stresses in the stamping body before the removal of external load. The unloading, while nominally linear elastic for most cases, departs from an ideal linear law [1-3].

Springback compensation by modifying tool geometry is difficult even for experienced tool makers. In practice, this springback compensation with the use of the "trial and error" method is still sometimes performed. It is possible to replace this method with finite element analysis (FEA), a numerical simulation that predicts the springback more accurately [4-6]. The finite element method (FEM) is a well-known tool for the prediction and analysis of sheet metal deformation $[7,8]$. The achieved results from forming simulations can be used to modify the geometry of the forming tool. Other solutions, regarding the springback reduction of the final stamped part, can include the design process to 
increase the rigidity of the stamping (reinforcing stampings with ribs) also suppressing, minimizing the springback effect, which can be achieved when drawing with a counter-pressure pad or using a variable blank holder force [5].

Therefore, research is mainly focused on the improvement of the springback prediction accuracy in the simulation software. There are four main categories of parameters which are crucial for the springback prediction in the numerical simulation. These categories include process, geometry, material and numerical parameters. The effects of material, process, geometry and numerical parameters on the springback prediction used in the numerical simulation are analyzed by numerous researchers.

Naofal et al. [9] studied the effects of hardening model and variation of elastic modulus on the springback prediction in roll forming. They observed a more accurate prediction of springback when the Yoshida-Uemori hardening model was used in the numerical simulation compared to isotropic hardening. Baara et al. [10] worked on the new constitutive hardening material model which can achieve more accurate springback predictions. The main objective of their work was to extend the Chord model to be able to reproduce the strain recovery point with non-zero residual stress, enabling a more accurate determination of springback. Tomáš et al. [11] conducted a numerical simulation of forming a box-shaped product to verify the experimental process results. They used Hill48, Hill90 yield functions in combination with Krupkowski and Hollomon hardening models. They found out that numerical simulation with Hill48 yield function in combination with Krupkowski hardening model showed minimal deviation from the experimental thickness results. Seo et al.'s [12] work was focused on the evaluation of the effects of constitutive equations on the springback prediction accuracy. They used two yield functions, Hill48 and Yld2000, in combination with the Yoshida-Uemori hardening model in the FEM simulation to predict the springback effect on the U-bend part and drawn T-shape part. Both parts were made of TRIP steel. They found out that it is essential to choose the right yield function to get an accurate prediction of springback. Mulidran et al.'s work was focused on the springback prediction of aluminum alloy car body stamping. The springback predictions were conducted with six yield functions (Barlat89, Barlat2000, Vegter-Lite, Hill90, Hill48 isotropic, and Hill48 orthotropic) combined with the Voce hardening model in numerical simulation. Springback analysis was carried out in three sections, and the numerical results were compared with the experimental values [13]. Thus, input material parameters are important for accurate forming and springback predictions.

The effect of the number of used integration elements in the sheet thickness on the springback prediction which is part of numerical parameters was studied by numerous authors. Li et al. [14] and Wagoner et al. [15] recommend using 25 to 51 elements to achieve 99\% accuracy of the springback prediction compared to the actual state. Some authors, for example, Xu et al. [16] and Yao et al. [17], recommend seven to nine points. The type of integration scheme also impacts springback prediction results. Yetna et al.'s [18] work was focused on the explicit and implicit springback simulation with the use of fully coupled ductile damage and distortional hardening model. They found that the springback results achieved with the use of the explicit integration scheme were more accurate than the results achieved with the implicit integration scheme. From the above-mentioned evidence, it can be stated that numerical parameters also play a significant role in numerical predictions of springback.

Lawanwong et al. [19] proposed a novel technology called "double-action bending" to eliminate springback of the stamped part made of advanced high-strength steel. They used FE analysis to determine process and tool parameters before the experiment try-out. Slota et al. [20] performed a numerical and experimental study in which the impact of the process parameters on the springback was studied. They found that higher values of blankholder force in combination with greater friction coefficient decrease the amount of springback of the hat-shaped part. Cui et al. [21] proposed a new stamping method for forming the L-shaped part. They call this method an electromagnetic-assisted stamping (EMAS). They used a magnetic force to control the springback phenomenon. The results showed that as discharge voltage increases, the bent angle after springback decreases. Therefore, 
research related to the springback phenomenon which is oriented on process parameters can significantly help with the reduction or elimination of the springback which appears after the forming process.

In this research work, a FEM was used to predict the springback of the hat-shaped part made of dual-phase steel HCT600X+Z. Numerous structural parts used in car bodies made of high-strength steels have a hat-shaped profile. This type of profile is also very often used in the research of the springback phenomenon. The finite element analysis was conducted to investigate the impact of used yield functions and hardening models on the springback prediction accuracy in numerical predictions. In this work, two types of tool designs were used and their impact on the springback was evaluated. The novelty of this work is the detailed analysis of the influence of the tool with a counterpunch on the springback values.

\section{Materials and Methods}

\subsection{Material}

In the presented work, hot-dipped galvanized dual-phase steel HCT600X+Z with a thickness of $0.80 \mathrm{~mm}$ was used as the blank. This dual-phase steel is a versatile material for the automotive industry due to its improved formability, capacity to absorb crash energy, and ability to resist fatigue. It is well known, that microstructure has a significant impact on the mechanical properties and elasto-plastic behavior of materials [22]. The microstructure of the material also impacts hardening behavior. The microstructure of dual-phase steel is different from the common types of steels, e.g., low carbon mild steels. Every material has its own, specific elasto-plastic behavior [23] therefore the results from other studies cannot be applied for other types of materials. The chemical composition of the experimental material is shown in Table 1. Material properties were measured by the uniaxial tensile test. Mechanical properties and formability parameters are shown in Table 2. To obtain the required data for the FEM model, the specimens for the uniaxial tensile test were cut in three different orientations $\left(0^{\circ}, 45^{\circ}\right.$ and $90^{\circ}$ to the rolling direction). Specimens for the uniaxial tensile test were produced according to the standard STN EN ISO 6892-1:2016 (Figure 1b). Properties of the material were measured according to the following standards: mechanical properties by STN EN ISO 6892-1:2016, the normal anisotropy ratio by STN EN ISO 10113:2006, and the strain hardening exponent by STN EN ISO 10275:2007. Tests were performed using the VEB TIW TIRAtest 2300 testing machine (TIRA Maschinenbau GmbH, Rauenstein, Germany) controlled by PC (Figure 1a).

Table 1. The chemical composition of the HCT600X $+Z$ steel.

\begin{tabular}{ccccccccccc}
\hline $\mathbf{C}$ & $\mathbf{M n}$ & $\mathbf{S i}$ & $\mathbf{P}$ & $\mathbf{S}$ & $\mathbf{A l}$ & $\mathbf{N b}$ & $\mathbf{T i}$ & $\mathbf{V}$ & $\mathbf{M o}$ & $\mathbf{C r}$ \\
{$[\%]$} & {$[\%]$} & {$[\%]$} & {$[\%]$} & $\begin{array}{c}\text { [\%] } \\
{[\%}\end{array}$ & {$[\%]$} & {$[\%]$} & {$[\%]$} & {$[\%]$} & {$[\%]$} & {$[\%]$} \\
\hline 0.090 & 1.890 & 0.260 & 0.014 & 0.001 & 0.026 & 0.001 & 0.003 & 0.002 & 0.002 & 0.010 \\
\hline
\end{tabular}

Table 2. The mechanical properties and formability parameters of the HCT600X $+Z$ steel.

\begin{tabular}{ccccccccccc}
\hline $\begin{array}{c}\text { Dir. } \\
{\left[{ }^{\circ}\right]}\end{array}$ & $\begin{array}{c}\mathbf{E} \\
{[\mathrm{GPa}]}\end{array}$ & $\begin{array}{c}\mathbf{R}_{\mathbf{p 0 . 2}} \\
{[\mathbf{M P a}]}\end{array}$ & $\begin{array}{c}\mathbf{R}_{\mathbf{m}} \\
{[\mathbf{M P a}]}\end{array}$ & $\begin{array}{c}\mathbf{A}_{\mathbf{8 0}} \\
{[\%]}\end{array}$ & $\begin{array}{c}r \\
{[-]}\end{array}$ & $\begin{array}{c}\boldsymbol{r}_{m} \\
{[-]}\end{array}$ & $\begin{array}{c}\Delta r \\
{[-]}\end{array}$ & $\begin{array}{c}n \\
{[-]}\end{array}$ & $\begin{array}{c}n_{m} \\
{[-]}\end{array}$ & $\begin{array}{c}\Delta n \\
{[-]}\end{array}$ \\
\hline 0 & & 405 & 656 & 24.4 & 0.745 & & & 0.197 & & \\
45 & 199 & 423 & 661 & 22.3 & 0.883 & 0.862 & -0.044 & 0.186 & 0.188 & 0.005 \\
90 & & 430 & 670 & 25.5 & 0.934 & & & 0.183 & & \\
\hline
\end{tabular}

where: E-Young's modulus, $\mathrm{R}_{\mathrm{p} 0.2}$-Yield stress, $\mathrm{R}_{\mathrm{m}}$-Ultimate tensile strength, $\mathrm{A}_{80}$-Total elongation, $r$-plastic strain ratio, $n$-strain hardening exponent, $n_{m}$-average value of strain hardening exponent, $r_{m}$-average value of plastic strain ratio $\Delta r$-planar anisotropy of plastic strain ratio, $\Delta n$-planar anisotropy of strain hardening exponent.

Four specimens were measured and tested at $0^{\circ}, 45^{\circ}$ and $90^{\circ}$ to the rolling direction to obtain the values of mechanical properties. The elongation was measured by the length extensometer (TIRA Maschinenbau GmbH, Rauenstein, Germany) and the width of the tested specimen was 
measured by width extensometer (TIRA Maschinenbau GmbH, Rauenstein, Germany). The precision level of both extensometers was $\pm 0.001 \mathrm{~mm}$. The strain hardening exponent was evaluated within an engineering strain of $5 \%$ to $15 \%$. The plastic strain ratio was evaluated at the engineering strain of $15 \%$.

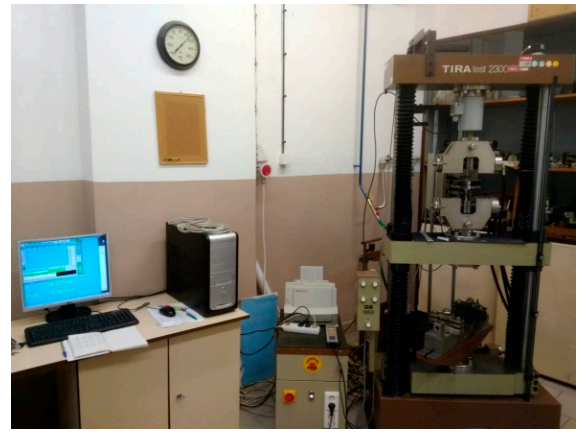

(a)

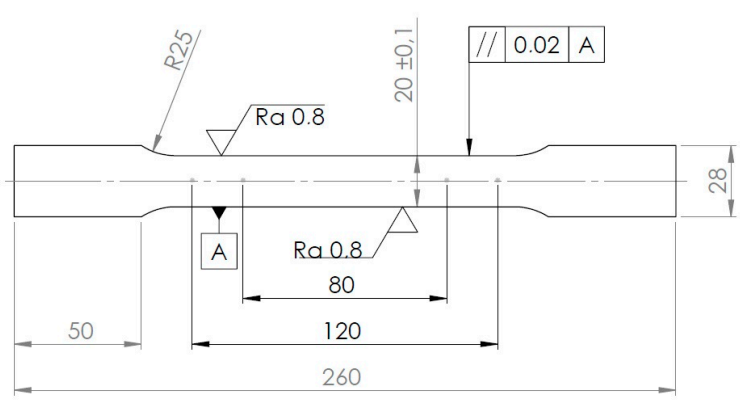

(b)

Figure 1. The uniaxial tensile test: TIRAtest 2300 testing machine (a); Specimen dimensions for the tensile test $[\mathrm{mm}](\mathbf{b})$.

The average values and planar anisotropy of the plastic strain ratio and the strain hardening exponent were calculated with the use of the following equations:

$$
\begin{aligned}
r_{m} & =\frac{1}{4}\left(r_{0^{\circ}}+2 \cdot r_{45^{\circ}}+r_{90^{\circ}}\right), \\
\Delta r & =\frac{1}{2}\left(r_{0^{\circ}}-2 \cdot r_{45^{\circ}}+r_{90^{\circ}}\right), \\
n_{m} & =\frac{1}{4}\left(n_{0^{\circ}}+2 \cdot n_{45^{\circ}}+n_{90^{\circ}}\right), \\
\Delta n & =\frac{1}{2}\left(n_{0^{\circ}}-2 \cdot n_{45^{\circ}}+n_{90^{\circ}}\right) .
\end{aligned}
$$

\subsection{Experimental Setup}

To investigate possible process/design solutions for the reduction of the springback of the hat-shaped part forming tool was designed. The main innovative part of this tool is the counterpunch which is opposite to the punch. The experimental tool was designed in such a way that it could be used in the TIRAtest 2300 testing machine. Figure 2a shows a forming tool without the counterpunch in the open position, the tool with the counterpunch is showed in Figure $2 \mathrm{~b}$.

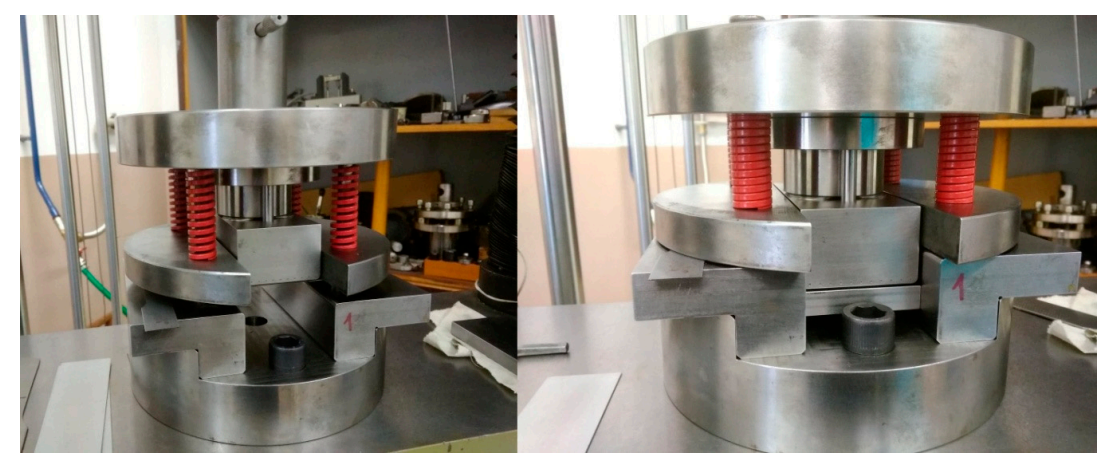

(a)

(b)

Figure 2. The experimental forming tool: Tool without counterpunch in the open position (a); Tool with counterpunch in the closed position (b). 
The dimensions of the experimental forming tool $[\mathrm{mm}]$ are depicted in Figure 3 . The punch corner radius $r_{p}$ and die corner radius $r_{d}$ was the same and equal to $3 \mathrm{~mm}$. Die clearance $c_{d}$ was $1 \mathrm{~mm}$. The forming speed $\mathrm{v}_{\mathrm{f}}$ was set to $20 \mathrm{~mm} / \mathrm{min}$. Stamping depth s was determined to $17 \mathrm{~mm}$. The maximum value of blankholder force $F_{b h}$ at the end of stamping stroke was $5.8 \mathrm{kN}$ and this force was applied by four springs. Two springs for each blankholder. The initial blankholder force value $F_{\text {bh }}$ applied to the blank was $0.9 \mathrm{kN}$. When counterpunch was used in the forming process its maximum force value $\mathrm{F}_{\mathrm{cp}}$ was $1.4 \mathrm{kN}$ at the end of the stamping stroke. Force was applied by one spring situated in the bottom center of the counterpunch, $7 \mathrm{~mm}$ before the end of the stamping stroke. All of the experiments were performed under dry conditions without lubrication. The springback was investigated on the hat-shaped part. The work-piece, the blank was a rectangular shape with dimensions of $40 \times 150 \mathrm{~mm}$. To examine the final shape of the sheet metal part springback angles $\alpha\left[^{\circ}\right]$ and $\beta\left[^{\circ}\right]$ defined in Figure 4 a were measured. Where angle $\alpha$ was measured with the use of tangent line between points $a$ ( $5 \mathrm{~mm}$ from the plane) and $b(10 \mathrm{~mm}$ from the plane). Springback angles were measured on 8 samples for each type of forming process. One arm of the stamped part was clamped to the precision steel block with the magnet. Taken photographic record was then imported into AutoCAD software (AutoDesk Inc., San Francisco, CA, USA) and springback angles $\alpha$ and $\beta$ were measured with the use of the software sketching tools. The ideal geometry and dimensions of this part [mm] are shown in Figure $4 b$.

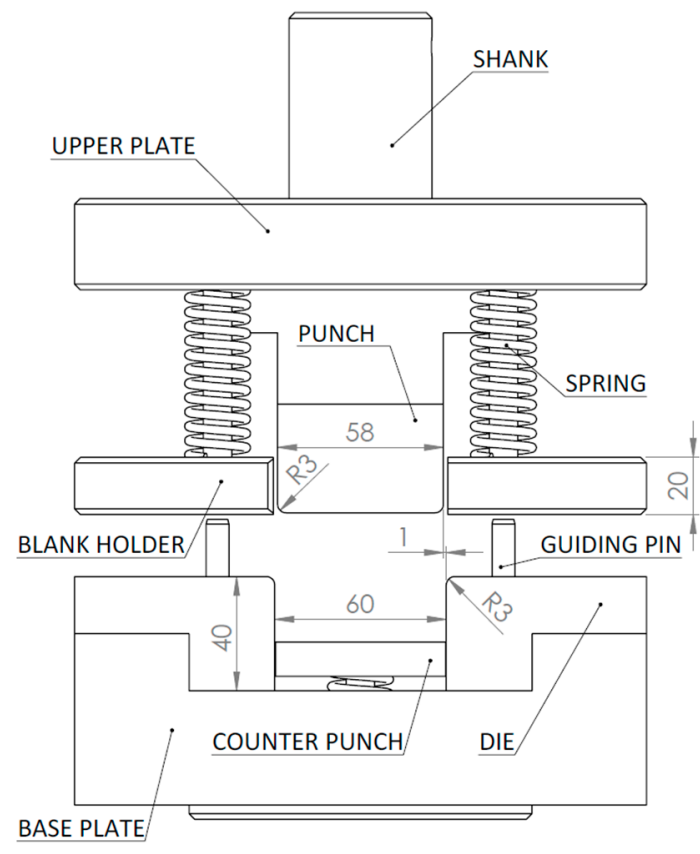

Figure 3. The experimental forming tool with the counterpunch.

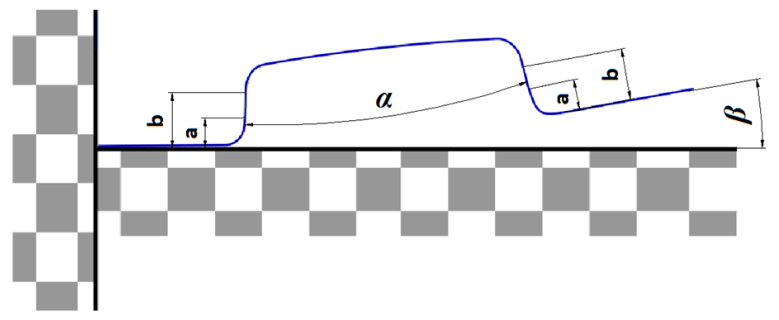

(a)

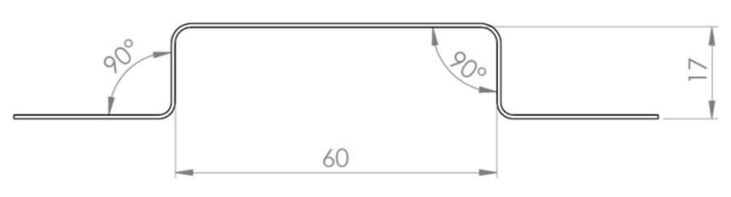

(b)

Figure 4. The experimental hat-shaped part: Measured springback angles $\left.\alpha{ }^{\circ}\right]$ and $\beta\left[{ }^{\circ}\right]$ (a); Ideal dimensions of the hat-shaped part (b). 


\subsection{Numerical Simulation}

Numerical springback predictions were conducted in the AutoForm software, version R3 (AutoForm Engineering GmbH, Wilen, Switzerland). This software uses a special implicit method and adaptive meshing algorithms. The tool geometry is an important factor in the sheet metal forming. Therefore, it is also important to correctly model forming tools that are then used in the numerical simulations. The CAD (Computer Aided Design) models of the experimental tools were used in numerical simulations, as shown in Figure 5. After importing CAD models into the CAE (Computer Aided Engineering) environment, the tool surfaces needed for the simulation were meshed with triangular shell elements. The blank shape and dimensions were the same as in physical experiments. The steel sheet rolling direction $\left(0^{\circ}\right)$ was positioned in the longitudinal axis of the hat-shaped part and centered.

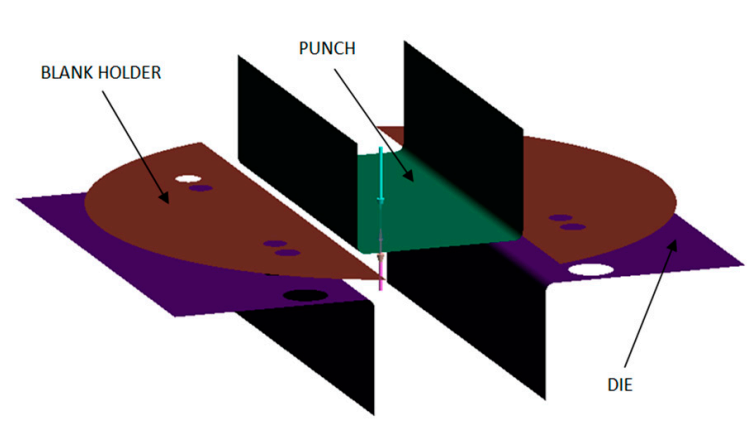

(a)

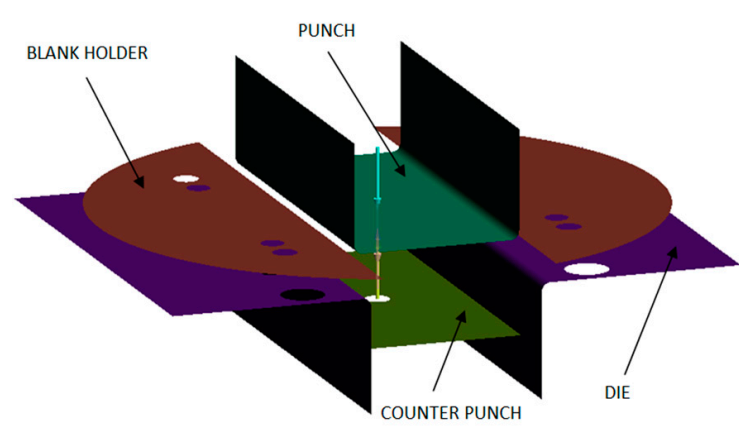

(b)

Figure 5. The tool models used in the numerical simulation: Forming tool with blank holder (a); Forming tool with blank holder and counterpunch (b).

The accuracy of the numerical simulation was set to fine. With this setting, the software automatically generates mesh parameters for tool surfaces. Blank and tool surfaces consisted of triangular elements. The size of the blank shell element was user defined and set to $0.8 \mathrm{~mm}$. Radius penetration was set to 0.16 and the number of integration points in the sheet metal thickness was set to 11, both of these parameters were set by the software. The maximum time step was set to $1.6 \mathrm{~s}$ and friction coefficient value was set to 0.30 by the user. The value of the friction coefficient is an important input parameter for the numerical simulation of deformation processes [24]. Its value is not only important in the forming processes, but it can be used for the energy absorption simulations of different types of structures [25,26].

Process parameters were the same as in the experiments. The forming speed $v_{f}$ was set to $20 \mathrm{~mm} / \mathrm{min}$ and stamping stroke s was $17 \mathrm{~mm}$ according to experimental values. The blankholder force $\mathrm{F}_{\mathrm{bh}}$ started at the $0.9 \mathrm{kN}$ value (initial contact of blank with blank holder) and raised to $5.8 \mathrm{kN}$ at the end of sheet metal forming simulation. When counterpunch was used in the forming simulation its maximum force value $\mathrm{F}_{\mathrm{cp}}$ was $1.4 \mathrm{kN}$ at the end of the stamping simulation. Counterpunch force was applied $7 \mathrm{~mm}$ before the end of the stamping stroke in simulation, same as in the physical experiment. All of the above mentioned process parameters were user defined.

The springback values $\alpha\left[^{\circ}\right]$ and $\beta\left[^{\circ}\right]$ were measured directly in the AutoForm software. This software uses a special tool for springback investigation, which includes springback angle measurement. It compares deformed mesh before and after the springback computation.

\subsubsection{Yield Surface}

One of the most important criteria in the sheet metal forming simulation is yield surface, also known as yield locus [10]. The yield surface describes the material transition from the elastic state to the plastic 
state. The relationship between stress components at the moment of yielding due to the multiaxial stress state during sheet metal forming is also expressed by yield surface. Therefore, the yield point obtained from the uniaxial tensile test is not sufficient to describe the yield surface [27]. In this work two yield criteria, Hill yield criterion and Barlat yield criterion were used to study the impact of yield surface model on the springback prediction (Figure 6). The anisotropy parameters for both yield criteria used in the simulation are defined in Table 3. The exponent value related to the crystallographic structure $M=6$ was user defined based on the BCC (body-centered cubic) crystal system of the material.

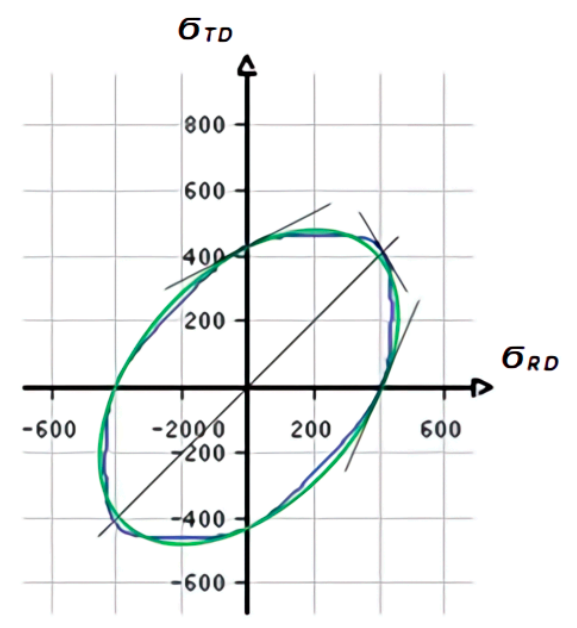

\section{- Hill Yield Locus _ Barlat Yield Locus}

Figure 6. Hill yield locus and Barlat yield locus used in FE analysis.

Table 3. The anisotropy parameters used for the description of yield criteria.

\begin{tabular}{ccccccccc}
\hline $\begin{array}{c}\text { Yield } \\
\text { Criterion }\end{array}$ & $\boldsymbol{r}_{\mathbf{0}}[-]$ & $\boldsymbol{r}_{\mathbf{4 5}}[-]$ & $\boldsymbol{r}_{\mathbf{9 0}}[-]$ & $\begin{array}{c}\sigma_{\mathbf{0}} \\
{[\mathrm{MPa}]}\end{array}$ & $\begin{array}{c}\sigma_{\mathbf{4 5}} \\
{[\mathbf{M P a}]}\end{array}$ & $\begin{array}{c}\sigma_{\mathbf{9 0}} \\
{[\mathrm{MPa}]}\end{array}$ & $\begin{array}{c}\sigma_{\text {biax }} \\
{[-]}\end{array}$ & $\begin{array}{c}\boldsymbol{M} \\
{[-]}\end{array}$ \\
\hline Hill48 & 0.745 & 0.883 & 0.926 & 405.2 & 410.6 & 430.0 & 1 & - \\
Barlat89 & 0.745 & 0.883 & 0.926 & 405.2 & 413.1 & 430.0 & 1.03 & 6 \\
\hline
\end{tabular}

Hill yield criterion was introduced in 1948 [28,29]. Hill proposed an anisotropic yield criterion which includes three orthogonal symmetry planes, which is described by the following quadratic function:

$$
2 f(\sigma)=(G+H) \sigma_{x x}^{2}+(F+H) \sigma_{y y}^{2}-2 H \sigma_{x x} \sigma_{y y}+2 N \sigma_{x y}^{2}
$$

where $\sigma_{x x}, \sigma_{y y}$, and $\sigma_{z z}$ are stresses in the RD $(x)$, TD $(y)$, and thickness $(z)$ directions, respectively; $\sigma_{x y}$, $\sigma_{y z}$, and $\sigma_{z x}$ are the shear stresses in $x y, y z$, and $z x$ directions. Parameters $F, G, H$, and $N$ are material parameters that describe the anisotropy of the material. If $F=G=H=1$ and $N=3$, the Hillus function is reduced to the von Mises criterion, or as it is called in FEM code, the Hill48 isotropic criterion. A more common description is based on normal anisotropy in the $0^{\circ}, 45^{\circ}$, and $90^{\circ}$ directions to the rolling direction. Then the material parameters $F, G, H$, and $N$ can be described by:

$$
F=\frac{r_{0}}{r_{90}\left(r_{0}+1\right)}, G=\frac{1}{r_{0}+1}, H=\frac{r_{0}}{r_{0}+1}, N=\frac{\left(r_{0}+r_{90}\right)\left(1+2 r_{45}\right)}{2 r_{90}\left(1+r_{0}\right)}
$$

The second yield criterion used in numerical simulations was Barlat yield criterion. The Barlat89 model needs three parameters for its complete formulation by which it is possible to describe the plane stress behavior. The formulation is the following [30]:

$$
f=a\left|k_{1}+k_{2}\right|^{M}+a\left|k_{1}-k_{2}\right|^{M}+(2-a)\left|2 k_{2}\right|^{M}=2 \sigma_{e}^{M}
$$


where $M$ is the exponent related to the crystallographic structure of the material $\sigma_{e}$ is the initial yield stress, $k_{1}$ and $k_{2}$ can be described as:

$$
k_{1}=\frac{\sigma_{x}+h \sigma_{y}}{2}, k_{2}=\left[\left(\frac{\sigma_{x}-h \sigma_{y}}{2}\right)+p^{2} \tau_{x y}^{2}\right]^{1 / 2}
$$

where $a, h$, and $p$ are the material model parameters identified by:

$$
a=\frac{2\left(\frac{\sigma_{e}}{\tau_{s 2}}\right)^{M}-2\left(1+\frac{\sigma_{e}}{\sigma_{90}}\right)^{M}}{1+\left(\frac{\sigma_{e}}{\sigma_{90}}\right)^{M}-\left(1+\frac{\sigma_{e}}{\sigma_{90}}\right)^{M}}, h=\frac{\sigma_{e}}{\sigma_{90}}, p=\frac{\sigma_{e}}{\tau_{s 1}}\left(\frac{2}{2 a+2^{M}(2-a)}\right)^{\frac{1}{M}}
$$

where $\tau_{s 1}$ and $\tau_{s 2}$ are yield stresses for two different types of shear tests: $\sigma_{12}=\tau_{s 1}$ for $\sigma_{11}=\sigma_{22}=0$ and $\sigma_{12}=0$ for $\sigma_{22}=-\sigma_{11}=\tau_{s 2}$. The identification procedure based on the coefficients $r_{0}$ and $r_{90}$ can be also used for the identification of parameters $a$ and $h$ :

$$
a=2-2 \sqrt{\frac{r_{0}}{1+r_{0}} \cdot \frac{r_{90}}{1+r_{90}}}, h=\sqrt{\frac{r_{0}}{1+r_{0}} \cdot \frac{1+r_{90}}{r_{90}}}
$$

The coefficient $p$ has to be calculated by a numerical procedure, by solving the non-linear equation or by using Equation (9) instead. In our case, the coefficient $p$ was achieved by solving the non-linear equation.

\subsubsection{Material Hardening Model}

To fully define material behavior during deformation, the hardening model is required. There are three main types of material hardening rules [31]. Isotropic hardening is where the yield surface remains the same shape, but expands with increasing stress. The second type, kinematic hardening, is where the yield surface remains the same shape and size, but translates in stress space. The last type of hardening behavior is combined hardening, also known as isotropic-kinematic hardening. This type of hardening is usually more complex and describes material behavior during deformation more accurately [19].

In this work, two isotropic hardening rules and two combined hardening rules were tested in numerical simulations. Isotropic hardening rules are defined as:

- $\quad$ Ludwik

$$
\sigma=K \cdot \varphi^{n}
$$

- Swift

$$
\sigma=K \cdot\left(\varphi_{0}+\varphi_{p l}\right)^{n}
$$

where $\sigma$ is the true stress, $K$ is the strength coefficient, $\mathrm{n}$ is the strain hardening exponent, $\varphi_{0}$ is the pre-strain and $\varphi_{p l}$ is the plastic strain. Material model constants used in both hardening rules are shown in Table 4. True stress-strain curves are shown in Figure 7.

Table 4. Ludwik and Swift material model constants.

\begin{tabular}{cccc}
\hline Model & $\boldsymbol{K}[\mathrm{MPa}]$ & $\boldsymbol{n}[-]$ & $\boldsymbol{\varphi}_{\mathbf{0}}[-]$ \\
\hline Ludwik & 1100 & 0.197 & - \\
Swift & 1070 & 0.183 & 0.00496 \\
\hline
\end{tabular}




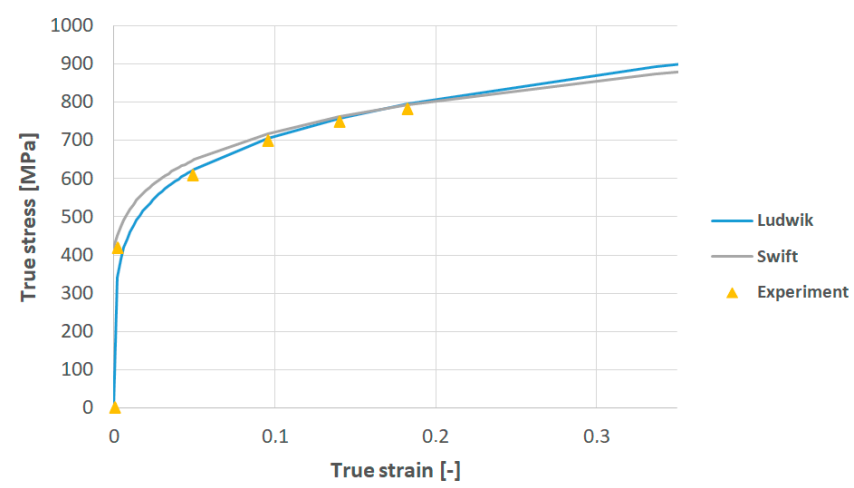

Figure 7. The True Stress-strain curves.

The combined isotropic-kinematic hardening models used in the numerical simulations are based on the isotropic hardening models mentioned above. These isotropic models were extended by the kinematic hardening model. Therefore, a combined hardening model was made. The kinematic hardening was defined by using the Kinematic module in Material generator by the simulation software.

This kinematic module consists of pre-defined parameters for different types of steels and aluminum alloys. The parameters, for this kinematic module, can be also manually defined based on the tensile-compression test. In this work, pre-defined parameters by the software for dual-phase steel were chosen. Kinematic hardening is described by four parameters in the software. The main idea of the AutoForm's kinematic model is to use equations to describe the early re-plastification (early yielding), degradation of elastic modulus and the transient softening.

With this model, a smooth stress function for the entire loading-reverse loading cycle is obtained. AutoForm's kinematic model is based on the work of Kubli et al. [32]. Material constants used in springback simulations with combined isotropic-kinematic hardening models are shown in Table 5. This model uses two main functions to describe behavior during kinematic hardening [33]:

$$
E_{l}=E_{0}\left[1-\gamma\left(1-e^{\kappa \varphi}\right)\right]
$$

where $E_{l}$ is the initial tangent modulus, $E_{0}$ is the initial tangent modulus at zero plastic strain (i.e., Young's modulus), $\gamma$ is a material parameter describing the reduction of the initial tangent modulus, $\varphi$ is equivalent plastic strain and $\kappa$ is the so-called saturation constant.

$$
\varepsilon_{r}=\varepsilon_{r l}+\varepsilon_{r n}=\frac{\sigma_{r}}{E_{l}(\varphi)}+K \cdot \operatorname{arctanh}^{2}\left(\frac{\sigma_{r}}{2 \sigma_{h}(\varphi)}\right)^{2}
$$

where $\varepsilon_{r}$ is the total reverse strain, $\varepsilon_{r l}$ is a linear reverse strain, $\varepsilon_{r n}$ is a non-linear reverse strain, $\sigma_{r}$ is reverse stress, $\sigma_{h}$ is isotropic stress and $K$ is a material parameter describing transient softening.

\begin{tabular}{|c|c|c|c|c|}
\hline Model & $\begin{array}{c}K \\
{[-]}\end{array}$ & $\begin{array}{c}\gamma \\
{[-]}\end{array}$ & $\begin{array}{c}\xi \\
{[-]}\end{array}$ & $\begin{array}{c}\boldsymbol{\kappa} \\
{[-]}\end{array}$ \\
\hline $\begin{array}{c}\text { Combined } \\
\text { (isotropic-kinematic) }\end{array}$ & 0.005 & 0.1 & 0.5 & 40 \\
\hline
\end{tabular}

Table 5. The material constants used in isotropic-kinematic hardening model.

\section{Results}

The results obtained from numerical prediction were compared with experimental ones. Experimentally measured springback angles $\alpha\left[^{\circ}\right]$ and $\beta\left[{ }^{\circ}\right]$ were compared with angles achieved in numerical simulations. Additionally, the influence of the proposed tool design on springback values 
was evaluated. Deviations of predicted springback angles $\alpha$ and $\beta$ from the experimental springback values for the conventional and forming tool with a counterpunch are also present.

\subsection{Analysis of Experimental Springback Results}

To investigate the impact of tool design on the springback phenomenon, two types of tool designs were experimentally tested. The conventional forming tool consisted of punch, die and blank holder. The proposed tool with counterpunch consisted of the same parts as a conventional forming tool, but with the addition of counterpunch. The shape comparison of two stampings made with the mentioned tool designs is shown in Figure 8. The force data measured during the forming of hat-shaped parts with the use of both tools are shown in Figure 9. Measured values of the springback angles $\alpha$ and $\beta$ are shown in Table 6 .

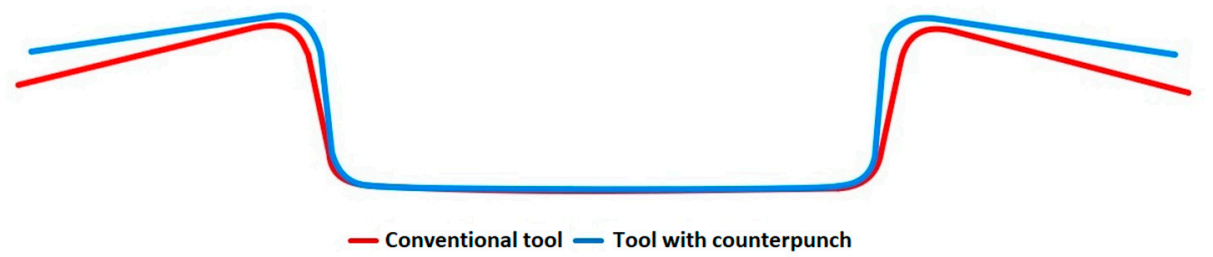

Figure 8. The shape comparison of stampings made with conventional (red) and counterpunch (blue) forming tool.

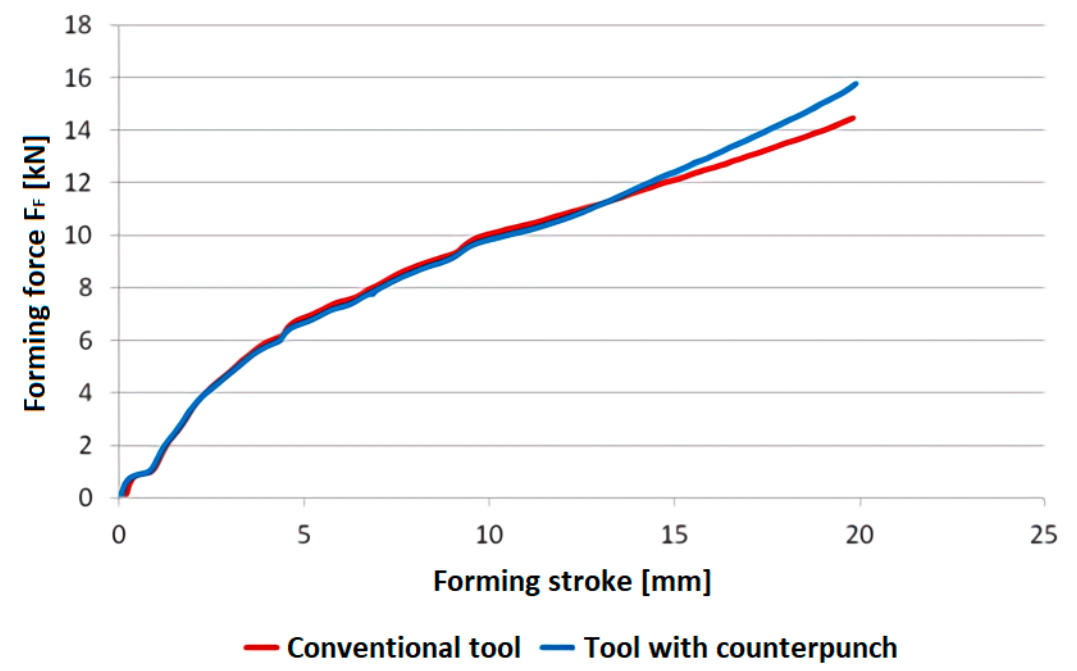

Figure 9. The Force-Stroke diagram obtained from experimental testing.

Table 6. The values of measured springback angles $\alpha / \beta$ and forming force $F_{F}$.

\begin{tabular}{cccc}
\hline Tool & $\alpha$ & $\beta$ & $\boldsymbol{F}_{\boldsymbol{F}}$ \\
& {$\left[{ }^{\circ}\right]$} & {$\left[{ }^{\circ}\right]$} & {$[\mathbf{k N}]$} \\
\hline Conventional & $24.5 \pm 0.6$ & $28.5 \pm 0.26$ & $14.4 \pm 0.11$ \\
With counterpunch & $12.4 \pm 1.03$ & $17.6 \pm 0.48$ & $15.8 \pm 0.20$ \\
\hline
\end{tabular}

Based on the profile comparison of the hat-shaped stampings, made with different types of tools, it can be stated, that the tool with counterpunch shows less springback of the part in comparison with a part made with the conventional tool. Springback angle $\alpha$ was reduced by $49 \%$ and springback angle $\beta$ was reduced by $38 \%$ when stamping was made with the tool with the counterpunch. The increase in Forming force $F_{F}$ is caused by the introduction of counterpunch force $F_{c p}$. 


\subsection{Analysis of Springback Prediction Results}

To study the effects of material models on springback predictions numerical simulations were performed. In these simulations, eight different combinations of material models were investigated (Table 7).

Table 7. The combinations of the used material models in the numerical simulation.

\begin{tabular}{cccc}
\hline Abbreviation & Yield Locus & Hardening Law & Isotropic-Kinematic Hardening \\
\hline HL & Hill48 & Ludwik & no \\
HLK & Hill48 & Ludwik & yes \\
BL & Barlat89 & Ludwik & no \\
BLK & Barlat89 & Ludwik & yes \\
HS & Hill48 & Swift & no \\
HSK & Hill48 & Swift & yes \\
BS & Barlat89 & Swift & no \\
BSK & Barlat89 & Swift & yes \\
\hline
\end{tabular}

Predicted values of springback angles $\alpha$ and $\beta$ with the use of different combinations of yield locus and hardening law for the tool with the counterpunch are shown in Figures 10 and 11. Predicted values of springback angles $\alpha$ and $\beta$ with the use of different combinations of yield locus and hardening law for the conventional tool are shown in Figures 12 and 13.

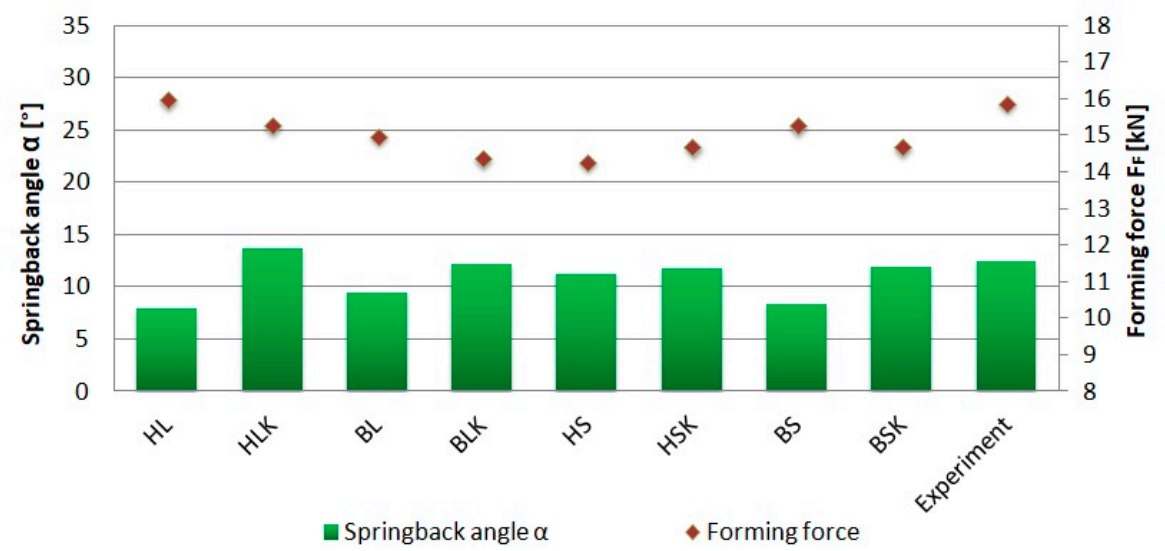

Figure 10. The predicted values of the springback angle $\alpha$ for the tool with the counterpunch.

Material models with combined hardening showed more accurate springback prediction results based on the numerical results of springback angle $\alpha$ when a tool with counterpunch was used in the simulation. The best correlation with experimental results was achieved using Barlat yield criterion in combination with the combined isotropic-kinematic hardening model based on the Ludwik hardening model. 


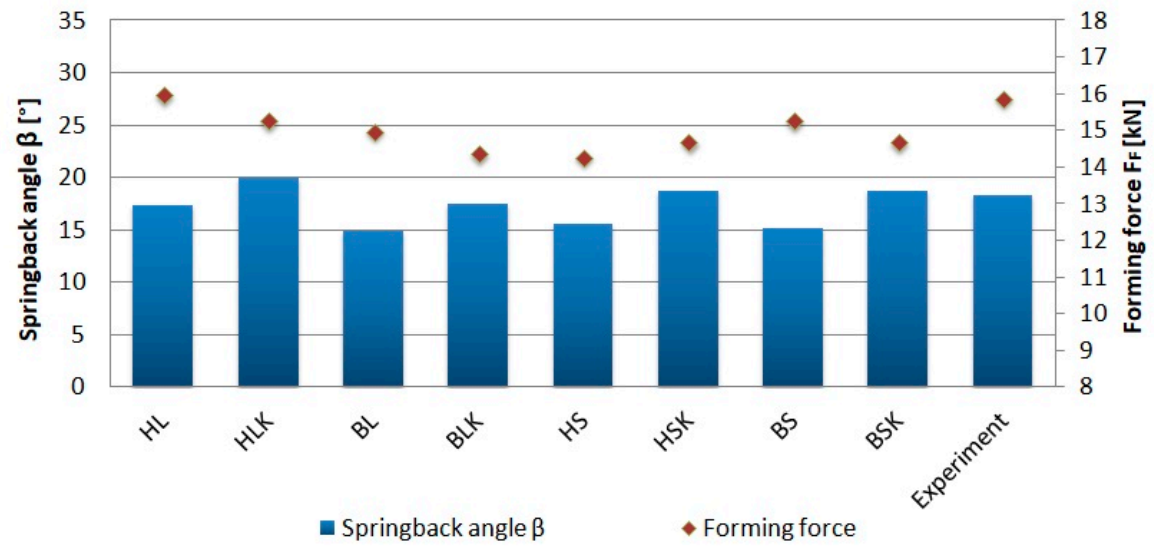

Figure 11. The predicted values of the springback angle $\beta$ for the tool with the counterpunch.

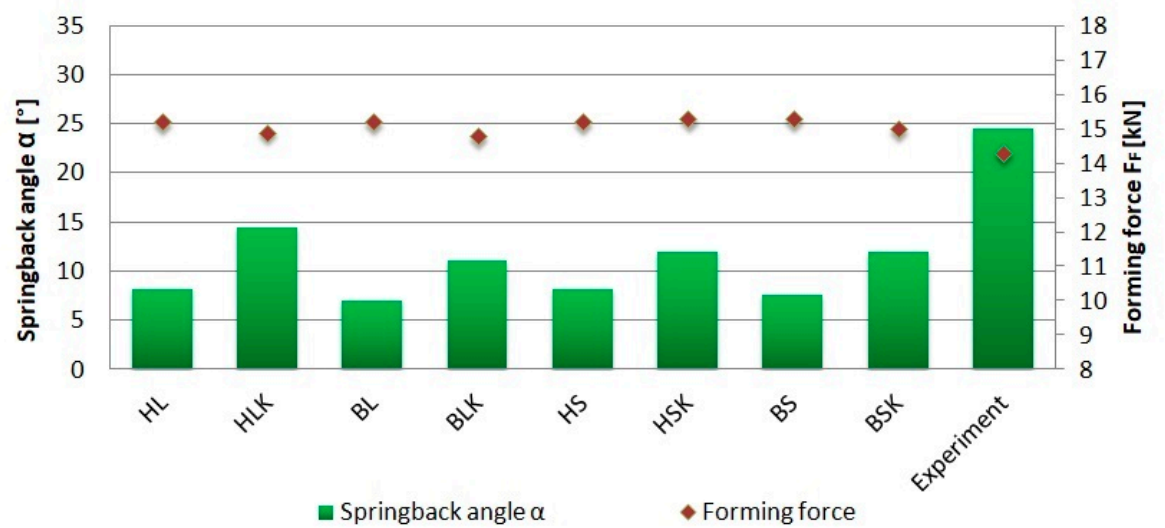

Figure 12. The predicted values of the springback angle $\alpha$ for the conventional tool.

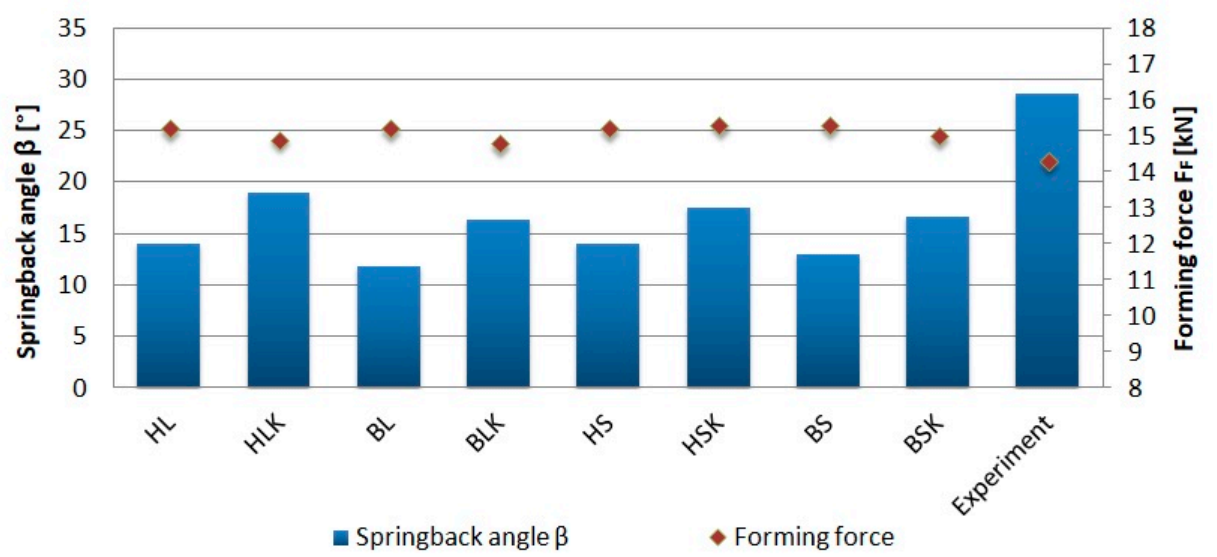

Figure 13. The predicted values of the springback angle $\beta$ for the conventional tool.

Predicted springback angle $\beta$ for the stamping made with the tool with the counterpunch showed the best correlation with experimentally obtained value $\beta$ when material yield criterion Barlat in combination with isotropic-kinematic (combined) hardening law was used, which is consistent with the springback angle $\alpha$ results. Springback prediction results obtained in numerical simulations, when a conventional tool was used, showed less accuracy in comparison with the springback results when the tool with counterpunch was adopted. In addition, the forming force $\mathrm{F}_{\mathrm{F}}$ was globally underestimated for the tool with the counterpunch.

The predicted values of $\alpha$ and $\beta$ with the least error, when a conventional tool was used, were achieved using the Hill yield criterion in combination with isotropic-kinematic hardening 
(based on the Ludwik hardening law). The numerical simulations conducted with this tool globally overestimated the maximum forming force $F_{F}$.

Deviations of predicted springback angles $\alpha$ and $\beta$ from the experimental springback values are shown in Tables 8 and 9. Deviations were calculated according to the formula:

$$
\operatorname{Dev} X=\frac{X_{\text {sim }}-X_{\text {exp }}}{X_{\text {exp }}} \cdot 100[\%]
$$

where $D e v X$ is a deviation of predicted springback angle value from the experimental angle value, $X_{\text {sim }}$ is the springback angle value and $X_{\text {exp }}$ is the experimental springback angle value.

Table 8. The deviations of predicted springback angles $\alpha$ and $\beta$ from the experimental springback values for the conventional forming tool.

\begin{tabular}{cccccccccc}
\hline $\begin{array}{c}\text { Evaluated } \\
\text { Parameters }\end{array}$ & HL & HLK & BL & BLK & HS & HSK & BS & BSK & Experiment \\
\hline $\boldsymbol{\alpha}\left[^{\circ}\right]$ & 8.2 & 14.4 & 7.0 & 11.1 & 8.2 & 12.0 & 7.6 & 12.1 & 24.5 \\
$\operatorname{Dev} \alpha[\%]$ & -66.5 & -41.2 & -71.4 & -54.7 & -66.5 & -51.0 & -69.0 & -50.6 & - \\
$\beta\left[^{\circ}\right]$ & 14.0 & 18.9 & 11.8 & 16.4 & 14.0 & 17.5 & 12.9 & 16.6 & 28.6 \\
$\operatorname{Dev} \boldsymbol{\beta}[\%]$ & -51.0 & -33.9 & -58.7 & -42.7 & -51.0 & -38.8 & -54.9 & -42.0 & - \\
\hline
\end{tabular}

Table 9. The deviations of predicted springback angles $\alpha$ and $\beta$ from the experimental springback values for the forming tool with counterpunch.

\begin{tabular}{cccccccccc}
\hline $\begin{array}{c}\text { Evaluated } \\
\text { Parameters }\end{array}$ & HL & HLK & BL & BLK & HS & HSK & BS & BSK & Experiment \\
\hline $\boldsymbol{\alpha}\left[^{\circ}\right]$ & 7.9 & 13.7 & 9.5 & 12.2 & 11.2 & 11.7 & 8.3 & 11.9 & 12.4 \\
$\operatorname{Dev} \boldsymbol{\alpha}[\%]$ & -36.3 & 10.5 & -23.4 & -1.6 & -9.7 & -5.6 & -33.1 & -4.0 & - \\
$\beta\left[^{\circ}\right]$ & 17.4 & 20 & 14.9 & 17.5 & 15.6 & 18.7 & 15.1 & 18.7 & 18.3 \\
$\operatorname{Dev} \boldsymbol{\beta}[\%]$ & -4.9 & 9.3 & -18.6 & -4.4 & -14.8 & 2.2 & -17.5 & 2.2 & - \\
\hline
\end{tabular}

To investigate the impact of the tool with the counterpunch on the springback, a strain path comparison for both tool designs was performed. The HLK and BLK material model were chosen for the strain path comparison. Three elements and points were selected in the area of highest deformation values as shown in Figure 14a. The obtained results are shown in Figure 14. When comparing the element in the middle of the wall width-red point-there is no change in the strain path. It is the plane strain state with the same value as the major strain. A change was found on the edge of the specimen - in the area of the lower wall radius (purple point) and in the middle of the wall (green point). In both cases, for the HLK material model, the major and minor strain increased to about $20 \%$ and $10 \%$ to $24 \%$, respectively. The major and minor strain of the purple and green element with the presence of the counterpunch, for the BLK material model, increased up to $22 \%$ and $5 \%$ to $10 \%$, respectively. The increase of the major and minor strain with the presence of the counterpunch is also observed for other regions, for both material models. The bright green points in the Forming Limit Diagram (FLD) are deformed elements that undergo thinning of more than $2 \%$ (in our case, it is the area of the part radiuses). The grey points represent deformed elements with less than $2 \%$ thinning. 


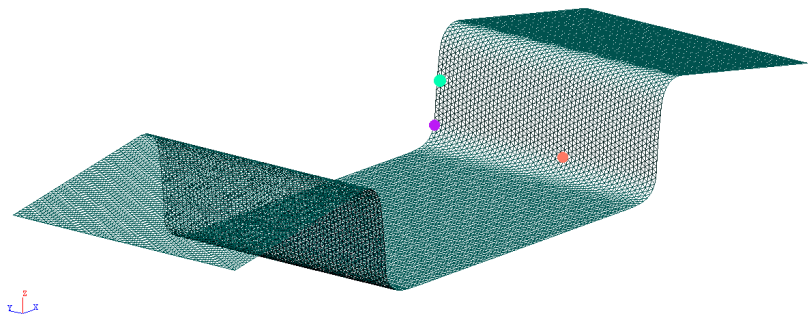

(a)

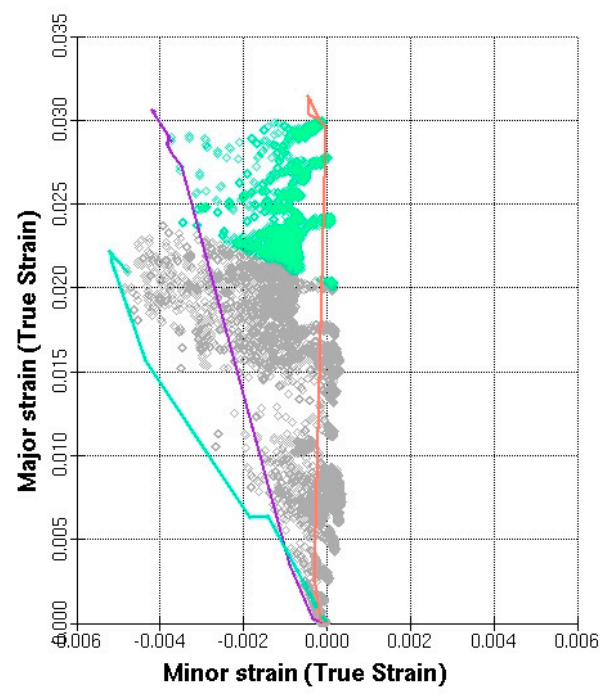

(b)

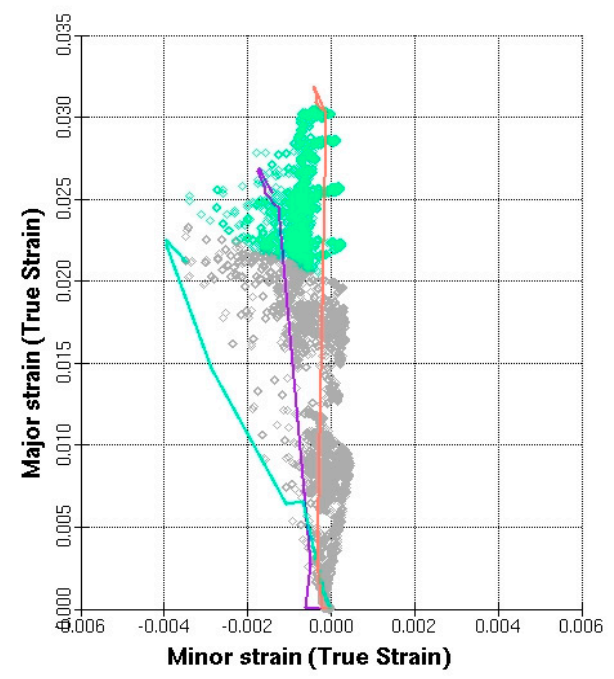

(d)

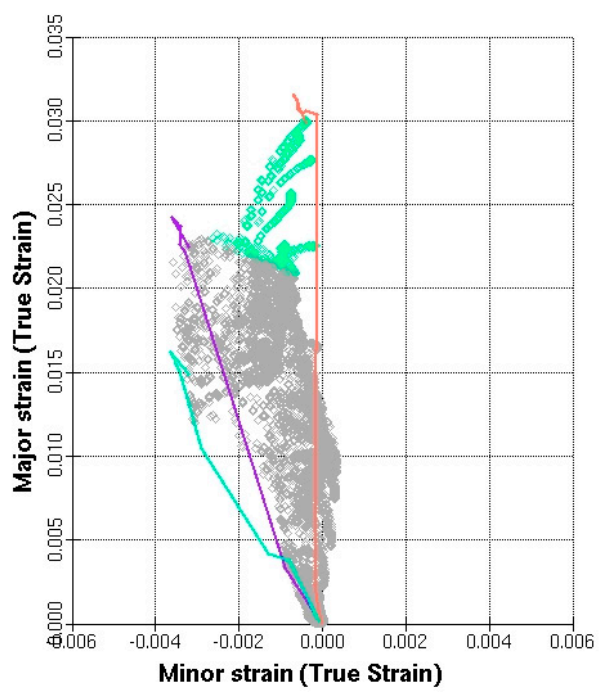

(c)

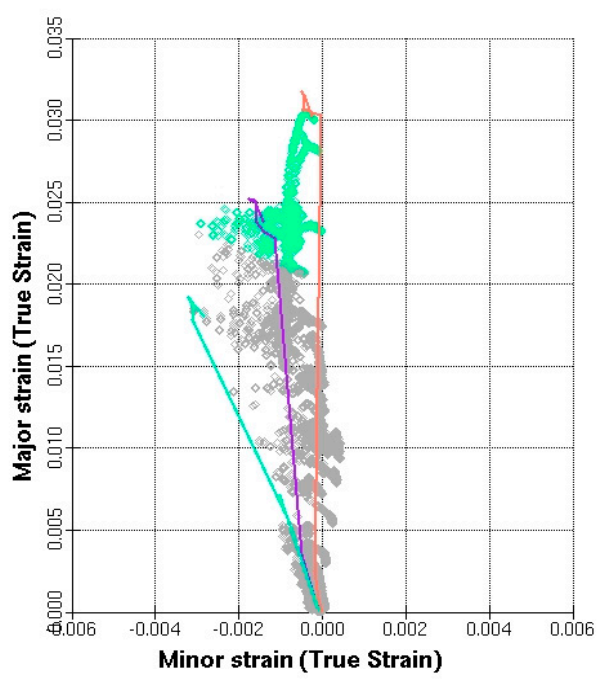

(e)

Figure 14. The comparison of strain paths: point selection for strain path evaluation (a); strain paths for the tool with the counterpunch (HLK model) (b); strain paths for the tool without the counterpunch (HLK model) (c); strain paths for the tool with the counterpunch (BLK model) (d); strain paths for the tool without the counterpunch (BLK model) (e). 


\section{Discussion}

Previously published research work on the springback prediction of stamped parts mainly focused on the investigation of material and process parameters and their impact on the springback prediction in numerical simulations $[11,13,15]$. Prediction and reduction of hat-shaped part springback made of dual-phase steel was the subject of the presented work. The research was focused on the numerical prediction of springback and the possible springback reduction measures achieved with the proposed tool design with the counterpunch. Other works $[18,20]$ were also aimed at springback reduction with the use of an innovative tool or process design. The work of Lawanwong et al. [19] involved double-action bending tool design which helped with springback reduction of the hat-shaped part.

The experimental results showed the importance of counter pressure for the reduction of the springback of the hat-shaped part. Measured angles $\alpha$ and $\beta$ were significantly reduced compared to the angles measured on the part made in the conventional tool, as shown in Table 6 . This reduction of the springback has a positive impact on the joinability of the stamped parts. The springback of the experimentally made hat-shaped part was measured and compared with numerical prediction results. Moreover, deviations of predicted springback angles $\alpha$ and $\beta$ from the experimental springback values for the innovative and conventional forming tools were calculated. The hardening model has a significant effect on the results of the simulation of sheet metal forming, as well as on springback prediction. The hardening model directly influences and describes the development of the plasticity surface during deformation/forming (change of size, shape, or its displacement). Our numerical results indicate that the Ludwik hardening law correlates better with the experimental results. A comparison of the Ludwik and Swift hardening laws is shown in Figure 7, which shows that at actual deformations up to 0.03 (corresponding to the major strain in bending for a given geometry and friction), the Ludwik hardening law more accurately describes the experimentally measured data from the tensile test.

It was found that combined isotropic-kinematic hardening models showed the best correlation of springback values with the experimentally measured ones. By using a combined istropic-kinematic hardening model, more accurate springback prediction results were obtained. The reason is that such a model includes the influence of the Bauschinger effect, which is present when changing the type of stress (change from tension to compression), e.g., in the deformation of the material on the tool radius (reduced yield in compression, work hardening stagnation, strain hardening and permanent softening), while this phenomenon is neglected in the isotropic hardening model. The achieved results can be applied for dry forming (process without lubrication) with a predominant plane strain (U-bending, V-bending, hemming, flanging). The smallest deviations of predicted springback values from the experimental ones, for the stamping made in the tool with the counterpunch, were achieved when Barlat yield criterion in combination with Ludwik hardening law and the kinematic module was used. The deviation of the angle $\alpha$ was $-1.6 \%$ and deviation of the angle $\beta$ was $-4.4 \%$. This measurement is supported by similar findings reported by Baara [10]. Their findings show that a combined (isotropic-kinematic) hardening model showed more accurate springback prediction. These results also comply with the works of Jin [8] and Naofal [9].

Additionally, the influence of yield locus on springback predictions was studied. Barlat and Hill yield criteria were tested in combination with isotropic and combined hardening models. When comparing the yield surfaces (Figure 6), it is clear that the yield stress for Hill48 is higher in the borderline cases of plane strain and shear, while for biaxial stress the yield stress is larger for Barlat function. For uniaxial tension, both yield surfaces have the same values. When forming a material with a predominant bend deformation, due to the width of the part, the plane strain is dominant. The increased value of the yield strength for the plane strain of the Hillus function will also be reflected in the greater springback of the stamped part compared to Barlat, which coincides with the results for the conventional tool concept. In the case of a tool with counter-punch, there is a change in the stress-strain state, where additional compressive stresses are created in the material by the counterpunch in the late stages of the forming operation. This may be the reason why Barlat was more 
suitable for a given type of tool design, which is in line with the comparison of Hill48 and Barlat for plane strain (Figure 6).

The predicted forming force $\mathrm{F}_{\mathrm{F}}$ was, in most cases, underestimated for the tool without counterpunch, although the simulations when tool with counterpunch was used overestimated forming force values in general. Possible reasons for this phenomenon include the constant value of the friction coefficient in numerical simulations which in real forming processes changes. Additionally, the combination of yield criterion and hardening law impacts the predicted values of the forming force $\mathrm{F}_{\mathrm{F}}$ as shown in Figures 10-13.

The combined isotropic-kinematic hardening model based on Ludwik hardening law showed the smallest deviations of predicted springback values from the experimental values, for both tool designs as shown in Tables 8 and 9. The reason for this might be higher predicted elastic deformation compared to Swift's hardening law. The deviation of the angle $\alpha$ for the BLK model was $-1.6 \%$, deviation for BSK was $-4.0 \%$ for the stamping produced in the tool with counterpunch. This measurement is supported by similar findings by Šiser [34]. The importance of a mathematical model for yield locus and hardening law is addressed by numerous authors $[18,20,35,36]$.

The reason for the lower springback values of the tool with the counterpunch can be explained by comparing strain paths of a deformed blank for both tool designs which are shown in Figure 14. When forming was conducted in the tool with the counterpunch, the maximum value of minor strain for the HLK and BLK material model has increased by $24 \%$ and $10 \%$, respectively. The reason for it is the introduction of additional compressive stress. Additionally, most of the elements were under higher stress, thus increasing the minor and major strain values of these elements, for both material models (Figure 14). The overall strain has increased, resulting in a reduction in the effect of the elastic strain. Thus, reducing the springback of the hat-shaped part.

\section{Conclusions}

Springback prediction accuracy is one of the most challenging problems in numerical simulation of forming processes. In the presented article, the influence of yield function and hardening laws on the accuracy of springback prediction of the hat-shaped part made of dual-phase HCT600X $+Z$ steel with the use of FEA was investigated. Additionally, tool design with the counterpunch for the reduction of springback was proposed. Based on the experimental and numerical results, the following outputs can be stated:

- Significant springback reduction, reduction in values of springback angles $\alpha$ (reduction of $49 \%$ ) and $\beta$ (reduction of $38 \%$ ) was achieved with the use of the tool design which includes counterpunch. This tool design can be adopted for stamping hat-shaped parts in industrial practice.

- The use of isotropic-kinematic combined hardening models showed more accurate springback prediction results compared to isotropic hardening models.

- Barlat yield criterion in combination with isotropic-kinematic hardening model based on Ludwik hardening law showed the best correlation in terms of springback prediction when a tool with counterpunch was used.

- Hill yield criterion in combination with isotropic-kinematic hardening model based on Ludwik hardening law achieved the most accurate springback prediction for the hat-shaped part made in the conventional tool.

- The springback prediction of the hat-shaped part made in the conventional tool was less accurate than the predictions of part made in the tool with a counterpunch.

Author Contributions: P.M., E.S., J.S. and M.T. designed the experiment; P.M. and J.S. performed the numerical simulations; P.M., M.T. and J.M. performed and evaluated the physical experiments; P.M., E.S., M.T. and J.M. analyzed the results; P.M. designed experimental tool and wrote the article. All authors have read and agreed to the published version of the manuscript. 
Funding: This research was funded by Slovak Research and Development Agency under project APVV-17-0381, by the project ITMS 26220220182, by the projects VEGA 1/0441/17, VEGA 1/0259/19 and VEGA 2/0080/19.

Conflicts of Interest: The authors declare no conflict of interest.

\section{References}

1. Chongthairungruang, B.; Uthaisangsuk, V.; Suranuntchai, S.; Jirathearanat, S. Springback prediction in sheet metal forming of high strength steels. Mater. Des. 2013, 50, 253-266. [CrossRef]

2. Banu, M.; Takamura, M.; Hama, T.; Naidim, O.; Teodosiu, C.; Makinouchi, A. Simulation of springback and wrinkling in stamping of a dual phase steel rail-shaped part. J. Mater. Process. Technol. 2006, 173, 178-184. [CrossRef]

3. Jeswiet, J.; Geiger, M.; Engel, U.; Kleiner, M.; Schikorra, M.; Duflou, J.; Neugebauer, R.; Bariani, P.; Bruschi, S. Metal forming progress since 2000. CIRP J. Manuf. Sci. Technol. 2008, 1, 2-17. [CrossRef]

4. Wagoner, R.H.; Lim, H.; Lee, M.-G. Advanced Issues in springback. Int. J. Plast. 2013, 45, 3-20. [CrossRef]

5. Yoshida, T.; Sato, K.; Hashimoto, K. Springback Problems in Forming of High-Strength Steel Sheets and Countermeasures. In Nippon Steel Technical Report No. 103; Nippon Steel \& Sumitomo Metal Corporation: Tokyo, Japan, 2013.

6. Toros, S.; Polat, A.; Ozturk, F. Formability and springback characterization of TRIP800 advanced high strength steel. Mater. Des. 2012, 41, 298-305. [CrossRef]

7. Wagoner, R.H. Advanced High Strength Workshop 2006; The Ohio State University: Columbus, OH, USA, 2006.

8. Jin, T.; Ha, N.; Goo, N. A study of the thermal buckling behavior of a circular aluminum plate using the digital image correlation technique and finite element analysis. Thin-Walled Struct. 2014, 77, 187-197. [CrossRef]

9. Naofal, J.; Naeini, H.M.; Mazdak, S. Effects of Hardening Model and Variation of Elastic Modulus on Springback Prediction in Roll Forming. Metals 2019, 9, 1005. [CrossRef]

10. Baara, W.A.B.; Baharudin, B.T.H.T.; Ariffin, M.K.A.M.; Ismail, M.I.S. Effect of Elastic Module Degradation Measurement in Different Sizes of the Nonlinear Isotropic-Kinematic Yield Surface on Springback Prediction. Metals 2019, 9, 511. [CrossRef]

11. Tomáš, M.; Evin, E.; Kepič, J.; Hudák, J. Physical Modelling and Numerical Simulation of the Deep Drawing Process of a Box-Shaped Product Focused on Material Limits Determination. Metals 2019, 9, 1058. [CrossRef]

12. Seo, K.-Y.; Kim, J.-H.; Lee, H.-S.; Kim, J.H.; Kim, B. Effect of Constitutive Equations on Springback Prediction Accuracy in the TRIP1180 Cold Stamping. Metals 2017, 8, 18. [CrossRef]

13. Mulidrán, P.; Šiser, M.; Slota, J.; Spišák, E.; Sleziak, T. Numerical Prediction of Forming Car Body Parts with Emphasis on Springback. Metals 2018, 8, 435. [CrossRef]

14. Li, X.; Yang, Y.; Wang, Y.; Bao, J.; Li, S. Effect of the material-hardening mode on the springback simulation accuracy of V-free bending. J. Mater. Process. Technol. 2002, 123, 209-211. [CrossRef]

15. Li, K.; Geng, L.; Wagoner, R. Simulation of springback w-ith the draw/bend test. In Proceedings of the Second International Conference on Intelligent Processing and Manufacturing of Materials. IPMM'99 (Cat. No.99EX296), Leuven, Belgium, 22-24 September 1999; Katholieke Universiteit Leuven: Heverlee, Belgium, 1999.

16. Xu, W.; Ma, C.; Li, C.; Feng, W. Sensitive factors in springback simulation for sheet metal forming. J. Mater. Process. Technol. 2004, 151, 217-222. [CrossRef]

17. Yao, H.; Liu, S.-D.; Du, C.; Hu, Y. Techniques to Improve Springback Prediction Accuracy Using Dynamic Explicit FEA Codes. SAE Tech. Pap. Ser. 2002, 111, 100-106. [CrossRef]

18. N’Jock, M.Y.; Houssem, B.; Labergère, C.; Saanouni, K.; Zhenming, Y. Explicit and implicit springback simulation in sheet metal forming using fully coupled ductile damage and distortional hardening model. In Proceedings of the 1st International Conference on Mechanical and Materials Science Engineering: Innovation and Research-2018, Maharashtra, India, 5-6 July 2018; AIP Publishing: Melville, NY, USA, 2018; Volume 1960, p. 090014.

19. Lawanwong, K.; Hamasaki, H.; Hino, R.; Yoshida, F. Double-action bending for eliminating springback in hat-shaped bending of advanced high-strength steel sheet. Int. J. Adv. Manuf. Technol. 2019, 106, 1855-1867. [CrossRef]

20. Slota, J.; Jurčišin, M.; Lăzărescu, L. Influence of technological parameters on the springback angle of high-strength steels. Acta Met. Slovaca 2014, 20, 236-243. [CrossRef] 
21. Cui, X.; Xiao, A.; Du, Z.; Yan, Z.; Yu, H. Springback Reduction of L-Shaped Part Using Magnetic Pulse Forming. Metals 2020, 10, 390. [CrossRef]

22. Barraza-Fierro, J.I.; Campillo-Illanes, B.; Li, X.; Castaneda, H. Steel Microstructure Effect on Mechanical Properties and Corrosion Behavior of High Strength Low Carbon Steel. Met. Mater. Trans. A 2014, 45, 3981-3994. [CrossRef]

23. Abspoel, M.; Scholting, M.E.; Lansbergen, M.; An, Y.; Vegter, H. A new method for predicting advanced yield criteria input parameters from mechanical properties. J. Mater. Process. Technol. 2017, 248, 161-177. [CrossRef]

24. Karagiozova, D.; Shu, D.; Lu, G.; Xiang, X. On the energy absorption of tube reinforced foam materials under quasi-static and dynamic compression. Int. J. Mech. Sci. 2016, 105, 102-116. [CrossRef]

25. Ha, N.S.; Lu, G.; Xiang, X. High energy absorption efficiency of thin-walled conical corrugation tubes mimicking coconut tree configuration. Int. J. Mech. Sci. 2018, 148, 409-421. [CrossRef]

26. Ha, N.S.; Lu, G.; Xiang, X. Energy absorption of a bio-inspired honeycomb sandwich panel. J. Mater. Sci. 2019, 54, 6286-6300. [CrossRef]

27. Wang, L.; Lee, T. The effect of yield criteria on the forming limit curve prediction and the deep drawing process simulation. Int. J. Mach. Tools Manuf. 2006, 46, 988-995. [CrossRef]

28. Hill, R. A theory of the yielding and plastic flow of anisotropic metals. Proc. R. Soc. Lond. Ser. A Math. Phys. Sci. 1948, 193, 281-297. [CrossRef]

29. Bruschi, S.; Altan, T.; Banabic, D.; Bariani, P.; Brosius, A.; Cao, J.; Ghiotti, A.; Khraisheh, M.; Merklein, M.; Tekkaya, A.E. Testing and modelling of material behaviour and formability in sheet metal forming. CIRP Ann. 2014, 63, 727-749. [CrossRef]

30. Barlat, F.; Brem, J.; Yoon, J.W.; Chung, K.; Dick, R.; Lege, D.; Pourboghrat, F.; Choi, S.-H.; Chu, E. Plane stress yield function for aluminum alloy sheets—Part 1: Theory. Int. J. Plast. 2003, 19, 1297-1319. [CrossRef]

31. Slota, J. Numerická Simulácia Lisovania Plechov, 1st ed.; Technical University of Košice: Košice, Slovakia, 2016; p. 194.

32. Kubli, W.; Krasovskyy, A.; Sester, M. Modeling of reverse loading effects including workhardening stagnation and early re-plastification. Int. J. Mater. Form. 2008, 1, 145-148. [CrossRef]

33. Tisza, M.; Lukacs, Z. Formability Investigations of High-Strength Dual-Phase Steels. Acta Met. Sin. Engl. Lett. 2015, 28, 1471-1481. [CrossRef]

34. Šiser, M.; Slota, J. Material Model of AW $5754 \mathrm{H} 11$ Al Alloy for Numerical Simulation of Deep Drawing Process. Acta Mech. Slovaca 2016, 20, 32-40. [CrossRef]

35. Neto, D.; Oliveira, M.; Alves, J.L.C.M.; Menezes, L.F. Influence of the plastic anisotropy modelling in the reverse deep drawing process simulation. Mater. Des. 2014, 60, 368-379. [CrossRef]

36. Neto, D.; Oliveira, M.; Santos, A.D.; Alves, J.; Menezes, L.F. Influence of boundary conditions on the prediction of springback and wrinkling in sheet metal forming. Int. J. Mech. Sci. 2017, 122, 244-254. [CrossRef]

(C) 2020 by the authors. Licensee MDPI, Basel, Switzerland. This article is an open access article distributed under the terms and conditions of the Creative Commons Attribution (CC BY) license (http://creativecommons.org/licenses/by/4.0/). 